\title{
Copies per Microgram
}

National Cancer Institute

\section{Source}

National Cancer Institute. Copies per Microgram. NCI Thesaurus. Code C126079.

A unit of concentration expressed as a number of copies per unit mass equal to one microgram. 